\title{
Study on the Effect of the Ambient Temperature toward the Quality of Sleep
}

\author{
Wira Hidayat bin Mohd Saad ${ }^{1}$, Khoo Chin Wuen², Masrullizam bin Mat Ibrahim³, \\ Nor Hashimah Binti Mohd Saad ${ }^{4}$, Syafeeza Binti Ahmad Radz, \\ Ahmad Sayuthi bin Mohamad Shokri ${ }^{6}$, Mohd Safirin bin Karis ${ }^{7}$ \\ 1,2,3,4,5 Faculty of Electronic and Computer Engineering, Universiti Teknikal Malaysia Melaka (UTeM), Melaka, Malaysia \\ ${ }^{6}$ Faculty of Engineering Technology, UTeM, Melaka, Malaysia \\ ${ }^{7}$ Faculty of Electrical Engineering, UTeM, Melaka, Malaysia
}

\begin{tabular}{l}
\hline \hline Article Info \\
\hline Article history: \\
Received Apr 12, 2017 \\
Revised Jul 30, 2017 \\
Accepted Aug 16, 2017
\end{tabular}

Keyword:

Ambient temperature Body condition parameters Sleep monitoring device User Interface Window application

\begin{abstract}
Getting enough sleep at the right times can help in improving quality of life and protect mental and physical health. This study proposes a portable sleep monitoring device to determine the relationship between the ambient temperature and quality of sleep. Body condition parameter such as heart rate, body temperature and body movement was used to determine quality of sleep. All readings will be log into database so that users can review back and hence analyze quality of sleep. The functionality of the overall system is designed for a better experience with a very minimal intervention to the user. The simple test on the body condition (body temperature and heart rate) while asleep with several different ambient temperatures are varied and the result shows that someone has a better sleep for the temperature range of 23 to 28 degree Celsius. This can prove by lower body temperature and lower heart rate.
\end{abstract}

Copyright $\odot 2017$ Institute of Advanced Engineering and Science. All rights reserved.

\section{Corresponding Author:}

Wira Hidayat bin Mohd Saad,

Faculty of Electronic and Computer Engineering,

Universiti Teknikal Malaysia Melaka,

Hang Tuah Jaya, 76100 Durian Tunggal, Melaka, Malaysia.

Email: wira_yugi@utem.edu.my

\section{INTRODUCTION}

Sleep is a type of "brain activity" that help to recover from brain fatigue [1]. Good sleep quality can contribute in many positive outcomes that helping a person to go through their day time activity [2]. When someone asleep, some of the measurable body condition such as heartrate, temperature, body movement and respiration rate are varied [3]. This parameter can also be used to determine some of the sleep abnormality including sleep apnea [3], [4]. The duration of without interrupt periods of sleep can be used to investigate the sleep continuity. To measure the movement of body during sleep stage, movement time (MT) and movement events (ME) are two important parameters to be measured.

Nowadays, there are many existing procedures and methods to measure the quality of sleep that use several different types of sensor and measurement to indicate the sleep stages. Polysomnography (PSG) for an example is used to measure the physiological variables including brain electrical activity, muscle movement respiratory effort and oxygen saturation [6]. Through this technique, researchers can identify sleep-onset and wake-up time [7]. A device must be worn on the wrist of user during sleep to measure their activity. The device must be placed on the user's wrist because it is believed that there is a strong connection between wrist movement and sleep status of the user [8]. The other method that is available is the use of video and audio recording together with Passive Infra-Red (PIR) sensor to detect the user sleep status [9]. The study in [10] presented a research on ambient sleep monitoring which using sensors that are installed 
inside living apartments. The type of sensors that had been used in this study include passive infrared (PIR) sensors as motion detection, contact sensors that had been attached to the windows and doors, temperature sensors to detect room temperature and sensors that can detect heat application usage and electricity.

In this study, our focus is to illustrate the relationship between temperature and sleep quality and for that purpose, the use of PC instead of smartphone is preferable because while we are in sleep, we did not require too much of mobility ergo $\mathrm{PC}$ with higher processing capability is more suitable than smartphone that allowing user to do a lot of processing and video recording. The developed sleep monitoring system is a combination of sensors and BLUNO microcontroller board to monitor and record the ambient parameters and body condition while user is sleeping. Our goal is to develop a sleep monitoring system that can be used at home and can do the monitoring in more than one night. Other than that, this monitoring system can help to determine the relationship of room ambient and quality of sleep.

\section{RESEARCH METHOD}

Figure 1(a) shows the overview of monitoring system which is consist of room ambient system and body condition system. Ambient monitoring system equips with, thermistor, LDR and DHT22 sensors to measure room temperature, light intensity and humidity respectively while portable body monitoring system equips with thermistor, accelerometer and heart pulse sensor. The ambient sensors and body condition sensors are connected to BLUNO and BLUNO NANO respectively to capture the input data and the data will display on the Window Application interface as shown in Figure 1(b). In this system, the room temperature, light intensity and humidity is the input for ambient sensor hence to measure heart rate, the pulse sensor is simply attach anywhere near to the blood vessel. The audio video recording is also capable by the system as it can be used to monitor the behavior of user during sleep. The development of the sleep monitoring system and the validation of each of the sensor use has been describe in [5].

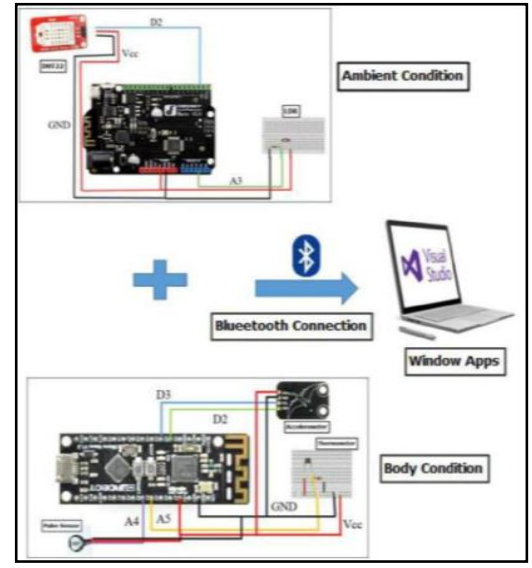

(a)

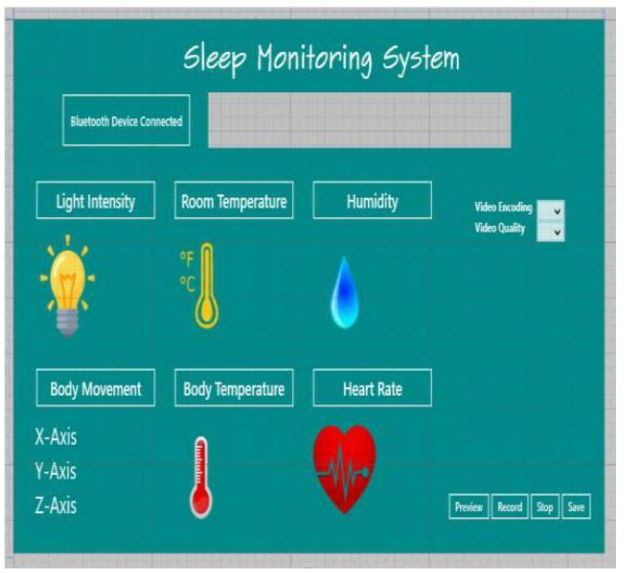

(b)

Figure 1. (a) The overview of hardware system and (b) is user interface of developed Window Application

Arduino IDE is programmed that consist of sensor algorithms to enable those sensors and to read the value that has been captured by each of room ambience system and body condition system. An application for PC was programed by Visual Studio to display the value of those parameters as can be seen in Figure 1(b). The sensor value is transferred between hardware part and software part via Bluetooth communication. The video recording using a webcam also included in this project. All the data that collected from two systems will be logged into MySQL database. This is enabling the user can view back the changes in body parameter during sleep stage. By this feature, user can console doctor to help them to analysis their sleep pattern.

The value of light intensity is obtained based on the digital value with a range between 0 and 1023 . Based on the study done in [11], value of light intensity can be identified subjectively by five different level ranging from very dark ( 1 to 9 ) to very bright (501 to 1023). Value ranging from 10 to 20 is indicate dark 
surrounding conditions, value 21 to 45 is indicated as dim condition and value ranges from 70 to 487 indicate bright surrounding.

The reading of room humidity was measured by using DHT22 sensor. The condition of room humidity can be subjectively separated into three category which are dry, medium or moist condition. The humidity reading for dry condition is ranging between 1 to $2 \% \mathrm{RH}$ that indicates a dry condition during sunny day such as in the afternoon and in the evening. For the moderate condition, the measured reading is between 3 to $8 \% \mathrm{RH}$. The reading indicates medium humidity in several surrounding conditions, such as during raining. The reading of humidity is ranging between 13 and $32 \% \mathrm{RH}$ which is referred to moist condition when there is raining for quite a long time and right after the raining when the temperature is low.

Temperature readings are divided into five different conditions which are very cold, cold, moderate, hot and very hot. Very cold conditions such as inside the room with air conditioner or during heavy rain in the midnight with the measured reading is recorded between 18 and 22 degrees Celsius. Cold condition has a range of temperature between 23 and 28 degrees Celsius. The reading for cold condition is obtained in early in the morning or right after a rain. The moderate condition has a range of temperature between 29 and 33 degrees Celsius. The reading is taken in the bedroom with a speed of fan 3 during the day or night. The temperature for very hot condition is between 37 and 40 degrees Celsius. The reading can be obtained outside the house in the afternoon or in the evening.

\section{RESULTS AND ANALYSIS}

The experiment Set 1 and Set 2 had been done on $27^{\text {th }}$ April 2017 and $28^{\text {th }}$ April 2017 respectively. These two set of experiments are carried out to observe the effect of ambient temperature toward quality of sleep. Both experiments are carrying out in Bukit Beruang, Melaka, Malaysia. The weather Set 1 is good which with $31^{\circ} \mathrm{C}$ room temperature and $7 \% \mathrm{RH}$ humidity which is in the moderate range. The lamp is turn off and just a little of light from outside is penetrated through the curtain that give the measure light intensity is in the dark range. Graph of the ambient parameters observation are shown as Figure 2 and Figure 3 for both set of experiments.

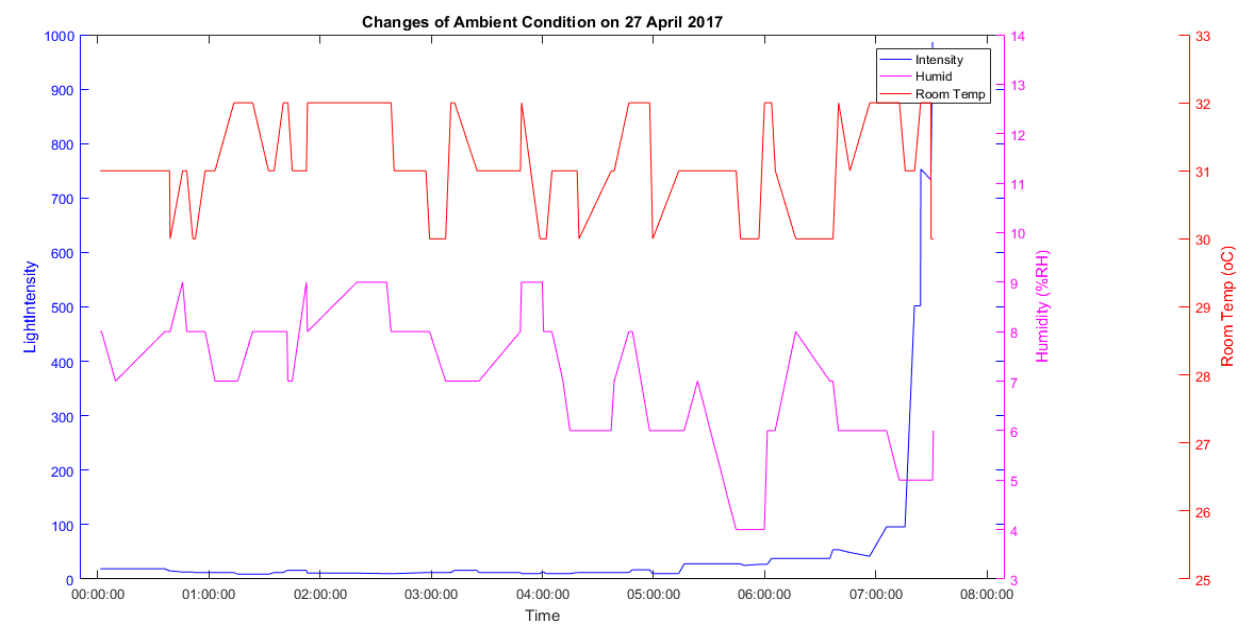

Figure 2. Changes in ambient condition in experiment Set 1

Ambient temperature for Set 2 is within the cold range which is between 23 to $28^{\circ} \mathrm{C}$. At the beginning, the room temperature is normal which is $32^{\circ} \mathrm{C}$ but there is a small rain at midnight which make the temperature decrease until $26^{\circ} \mathrm{C}$. Raining make the average room temperature become $28^{\circ} \mathrm{C}$. The humidity and light intensity are maintained within the same range as in Set 1 condition.

Figure 4 and Figure 5 shows the changes of body condition in two nights that can be distinguished into several sleep stages. By observing the pattern from plotted graph, the sleep stage of Non-Rapid Eye Movement (NREM) and Rapid Eye Movement (REM) can be been determined. There are more changes of body movement during the transition stage but the body temperature and heart rate do not change much 
during this stage. Then, there are some changes in heart rate and body temperature in next stage which is light sleep stage. The body temperature and heart rate are slightly decreased in this stage. Someone is difficult to wake up at this stage so the body movement did not change more. Next sleep stage is called as deep sleep stage. At this stage, the heat rate and body temperature become increase as blood supply to muscle increase. Someone is more potential to the surrounding disturbance so that fewer changes in body movement in this deep sleep stage. Other than that, someone will feel disoriented for several minutes if woken during this stage. Final sleep stage in one cycle is called as dream sleep stage and it is REM where the dream is occurred. At this stage, body temperature and heart rate will increase and more changes in body movement. The duration spent for each sleep stage had been analysis and compare with the normal duration sleep cycle and based on the duration of each sleep stage, the quality of sleep can be determined.

The comparison on changes of ambient condition and changes of body condition in each sleep stage had been summarized into Table 1 and Table 2. From the summary of result for both set of experiment, it shows that the suitable ambient condition for people to sleep better is in a cold environment. This conclusion is made based on the time spent for transition stage for Set 2 is only 12 minutes which is a normal time for a person to fall asleep while sample takes longer time to fall asleep in experiment Set 1. Dream sleep stage is the stage where the dream happens and normally only takes 90 minutes to 120 minutes after fall asleep. In experiment Set 2, it shows that sample only spends 1 hour and 28 minutes which in the good range while 2 hours in experiment Set 1 which is also in the good range as well. This shows that sample can sleep better in environment Set 2 rather than Set 1. Besides that, the time to complete one sleep cycle in experiment Set 2 is shorter than experiment Set 1.
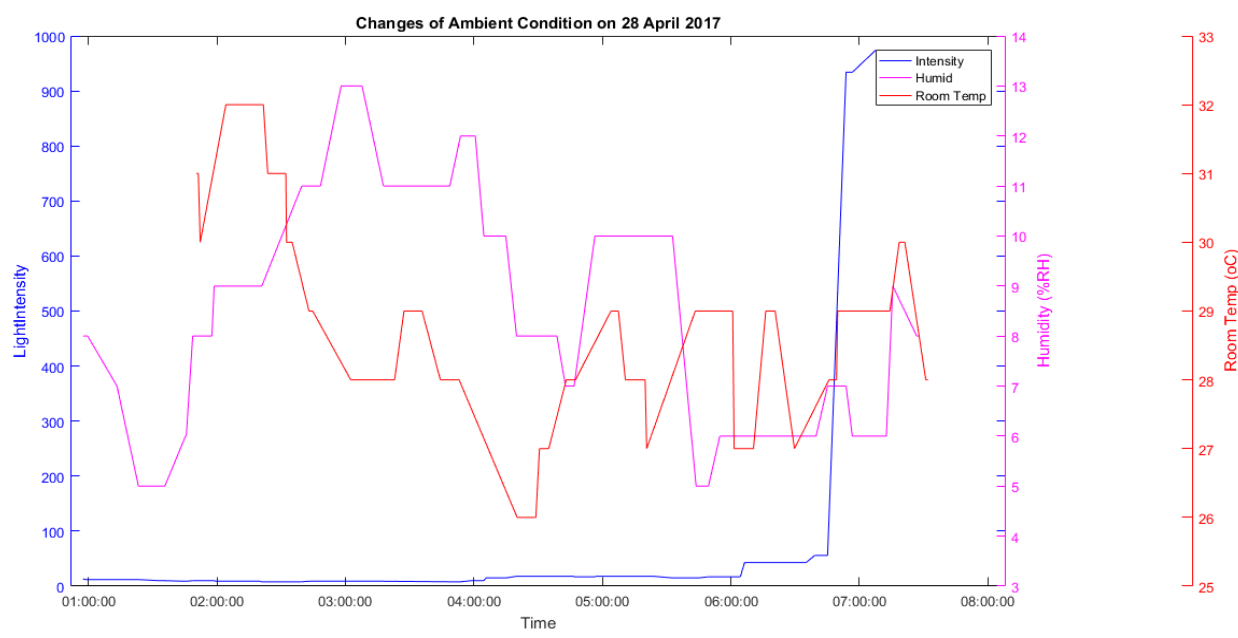

Figure 3. Changes in ambient condition in experiment Set 2
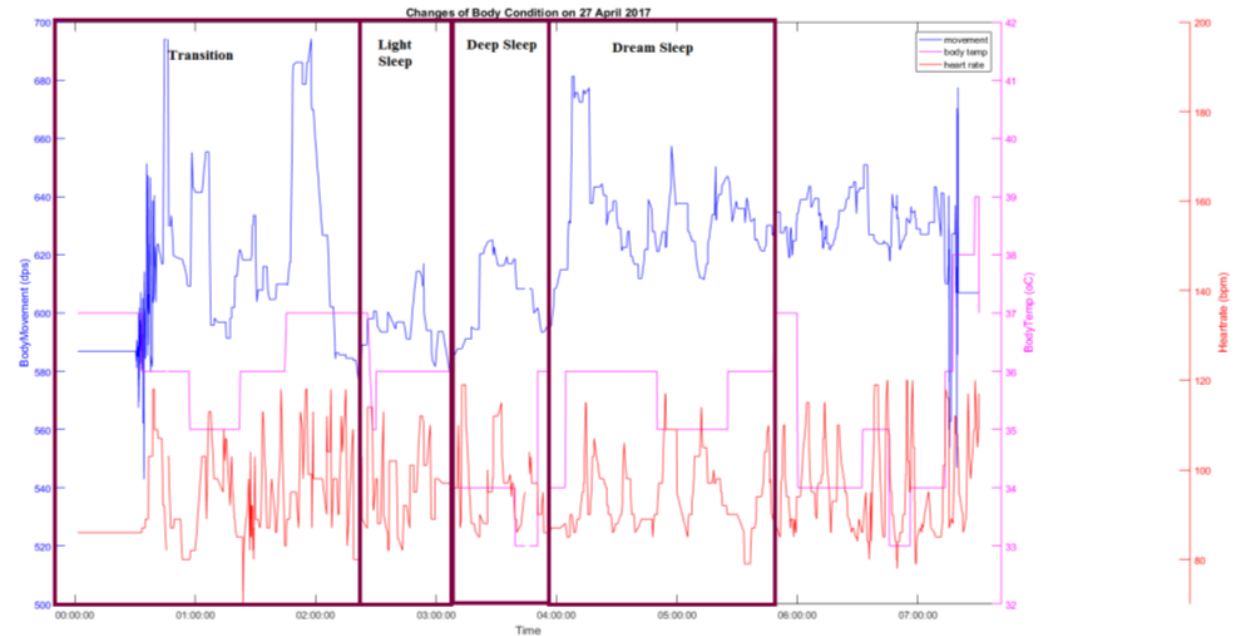

Figure 4. Changes in body condition in experiment set 1 

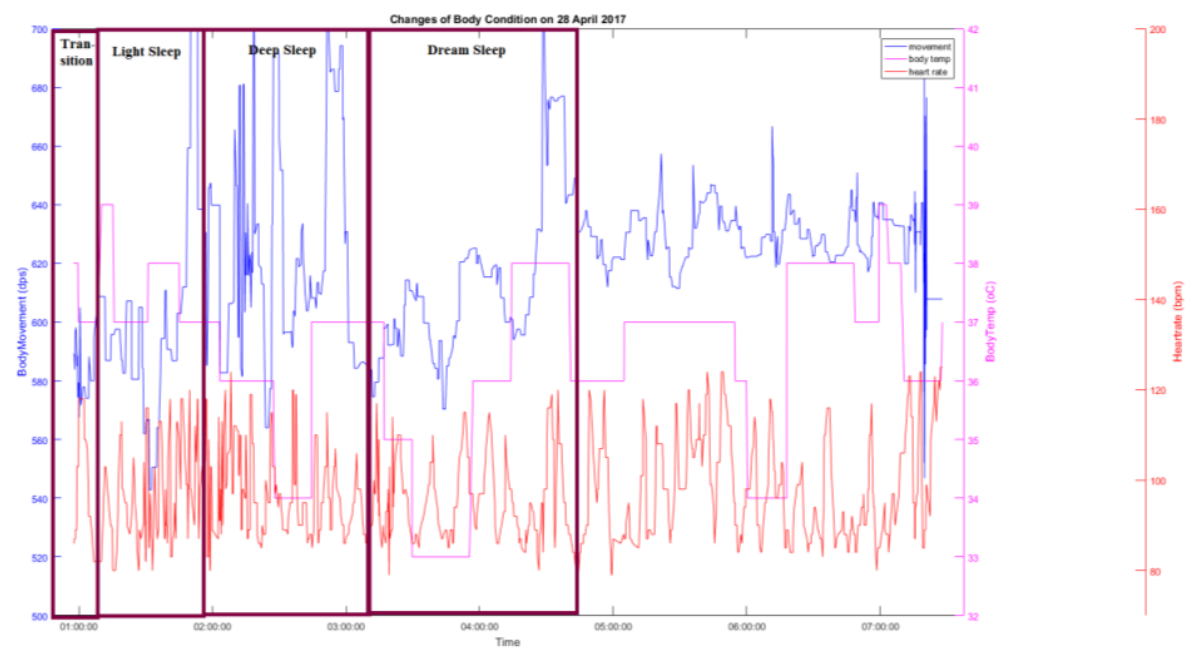

Figure 5. Changes in body condition in experiment Set 2

Table 1. Summary of ambient condition data in experiment set 1 and 2

\begin{tabular}{cccc}
\hline \multicolumn{2}{c}{ Parameter } & Set 1 & Set 2 \\
\hline Room Temperature & Maximum & 32 & 31 \\
$\left({ }^{\circ} \mathrm{C}\right)$ & Minimum & 30 & 26 \\
& Average & 31 & 28 \\
Humidity & Maximum & 9 & 13 \\
$(\% \mathrm{RH})$ & Minimum & 4 & 5 \\
& Average & 7 & 8 \\
Light & Maximum & 986 & 974 \\
Intensity & Minimum & 9 & 8 \\
& Average & 153 & 188 \\
\hline
\end{tabular}

Table 2. Summary of body condition data and analysis the sleep cycle in experiment set 1 and 2

\begin{tabular}{cccc}
\hline Parameter & & Set 1 & Set 2 \\
\hline Body Temperature & Transition & $35-37$ & $37-39$ \\
$\left({ }^{\circ} \mathrm{C}\right)$ & Light Sleep & $34-36$ & $37-39$ \\
& Deep Sleep & $33-36$ & $34-36$ \\
& Dream Sleep & $33-38$ & $33-39$ \\
Heart Rate & Transition & $91-114$ & $82-118$ \\
$(\mathrm{BPM})$ & Light Sleep & $82-113$ & $80-113$ \\
& Deep Sleep & $85-119$ & $85-124$ \\
Body Movement & Dream Sleep & $78-120$ & $79-124$ \\
& Transition & More & More \\
& Light Sleep & Less & More \\
& Deep Sleep & More & Less \\
REM & Dream Sleep & Less & $0057-0110(12 \mathrm{mins})$ \\
Sleep Cycle & Transition & $0030-0228(2$ hours $)$ & $0110-0158(48 \mathrm{mins})$ \\
& Light Sleep & $0230-0304(44 \mathrm{mins})$ & $0159-0312(1 \mathrm{hour} 13 \mathrm{mins})$ \\
& Deep Sleep & $0304-0353(49 \mathrm{mins})$ & $0312-0440(1 \mathrm{hour} 28 \mathrm{mins})$ \\
\hline
\end{tabular}

\section{CONCLUSION}

At the end of this project, a portable sleep monitoring system for ambience and body condition have been demonstrate. Based on the testing of the device toward the effect of the room temperature toward the quality of sleep shows that a person has a good quality of sleep in a cold condition range which is between 23 and 28 degrees Celsius. This showed that a person can easy fall asleep in a cold environment.

\section{ACKNOWLEDGEMENTS}

The authors would like to thank to the Machine Learning \& Signal Processing (MLSP) research group under Center for Telecommunication Research and Innovation (CeTRI) and Rehabilitation Engineering 
\& Assistive Technology (REAT) research group under Center of Robotics \& Industrial Automation (CeRIA) of Universiti Teknikal Malaysia Melaka (UTeM), Faculty of Electronics and Computer Engineering (FKEKK), UTeM for the use of the existing facilities to complete this project and Ministry of Higher Education (MOHE), Malaysia for sponsoring this work under project RAGS/1/2014/ICT06/FKEKK/B00065.

\section{REFERENCES}

[1] Takuji Suzuki, et al,. "Development of a Sleep Monitoring System with Wearable Vital Sensor for Home Use", National Institute of Occupational Safety and Health.

[2] Allison G. Harvey, et al., "The Subjective Meaning of Sleep Quality: A Comparison of Individuals with and without Insomnia", SLEEP, pp. 384-393, 2008.

[3] Stages of Sleep. (n.d.). Retrieved May 14, 2016, from https://web.mst.edu

[4] Wei Zhao, et al. “Automated Sleep Quality Measurement using EEG Signal,” pp1079- 1082, 2010.

[5] W. H. M. Saad, C. W. Khoo, S. I. Ab Rahman, M. M. Ibrahim, N. H. M. Saad, "Development of sleep monitoring system for observing the effect of the room ambient toward the quality of sleep", IOP Conference Series: Materials Science and Engineering, Volume 210, conference 1

[6] Sadeh A, et al. "Activity-based sleep-wake identification: an empirical test of methodological issues," 17(3), 201-207, 1994.

[7] Ir. R. (Reinder) Haakmaa, et al., "Unobtrusive Sleep Monitoring," Proceedings of Measuring Behavior 2012, pp122-124, 2012.

[8] Ancoli-Israel, et al., "The role of actigraphy in the study of sleep and circadian rhythms," Sleep, 2012.

[9] Ya-Ti Peng, et al. "Multimodality Sensor System for Long-Term Sleep Quality Monitoring," IEEE Transactions on Biomedical Circuits and Systems, 1(3), 217-227, 2008.

[10] Andrea Kealy, et al., "Derivation of Night Time Behaviour Metrics using Ambient Sensors," International Conference on Pervasive Computing Technologies for Healthcare and Workshops, 33-40, 2013.

[11] W.H.B. M. Saad, et al, "Development of Sleep Monitoring System to Observe the Effect of Room Ambient toward the Quality of Sleep," 2017.

[12] Lund, H. G, et al. "Sleep Patterns and Predictors of Disturbed Sleep in a Large Population of College Students," Journal of Adolescent Health, 46(2), pp124-132,2010.

\section{BIOGRAPHIES OF AUTHORS}

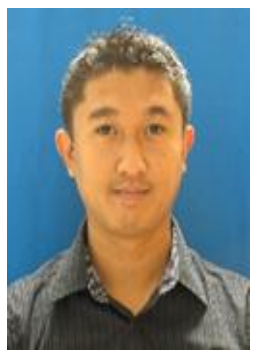

Wira Hidayat bin Mohd Saad. Currently working as a senior lecturer in Department Computer, Faculty of Electronics and Computer Engineering (FKEKK), Universiti Teknikal Malaysia Melaka UTeM. He finished his degree in Bachelor of Electrical and Electronics Engineering from UPM, Malaysia in 2007 and he finished his PhD study in 2013 in the field of Multimedia Systems Engineering from the same university. His research interest is in the field of medical imaging and monitoring, image and signal processing, and embedded system design and application.

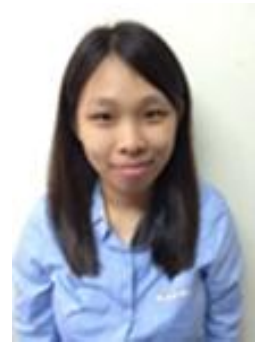

Chin Wuen Khoo was a graduate student in Faculty of Electronic and Computer Engineering from UTeM (2017). His area of interests includes embedded system, signal processing and sleep study.

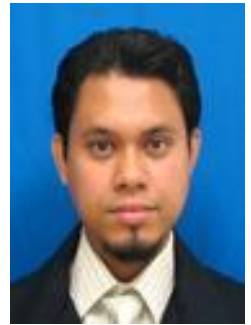

Masrullizam bin Mat Ibrahim is currently working as a senior lecturer in Department Computer, FKEKK, UTeM. He finished his study in Bachelor of Engineering (Electrical Engineering Electronics) and Master of Engineering (Electrical-Electronics \& Telecommunications) from UTM, Malaysia and finished his PhD in Electronics Engineering from University of Strathclyde, UK. His research areas are in digital system, VHDL design and electronics. 


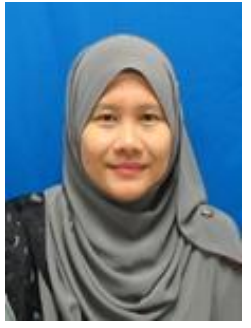

Nor Hashimah Binti Mohd Saad is currently working as a senior lecturer in Department Computer, FKEKK, UTeM. He finished his study in Bachelor of Engineering (Electrical Engineering - Medical Electronics), Master of Engineering (Electrical-Electronics \& Telecommunications) and $\mathrm{PhD}$ in Medical Image Processing from UTM, Malaysia UK. His research areas are in digital signal processing, medical electronics, MRI

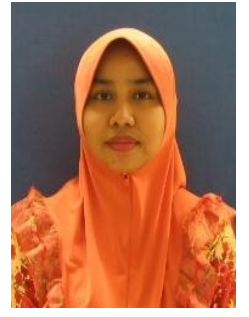

Syafeeza Binti Ahmad Radz is currently working as a senior lecturer in Department Computer, FKEKK, UTeM. He finished his study in Bachelor of Engineering (Electrical Engineering Electronics), Master of Engineering (Electrical-Electronics \& Telecommunications) and $\mathrm{PhD}$ in Electrical Engineering from UTM, Malaysia UK. His research areas are in embedded system, pattern recognition, machine learning, image processing

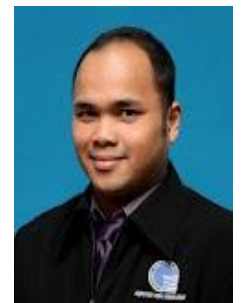

Ahmad Sayuthi bin Mohamad Shokri is currently working as a lecturer in Faculty of Engineering Technology, UTeM. He finished his study in Bachelor of Engineering (Hons) in Electronic Engineering (Computer), UTeM and Master of Engineering form UKM, Malaysia. His specialization is in PBL, TVET and signal processing.

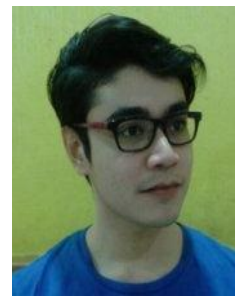

Mohd Safirin bin Karis is currently working as a lecturer in Faculty of Electric Engineering, Universiti Teknikal Malaysia Melaka. He finished his study in Bachelor of Engineering (Electrical Engineering -Telecommunications) and Master of Engineering (Mechatonic \& Control Automation) from UTM, Malaysia. His specialization is in telecommunications, and control, instrumentation and automations. 